\title{
Assessing the dimensional stability of alkali-activated calcined clays in the fresh state: a time-lapse X-ray imaging approach
}

\author{
Luca Valentini $(\mathbb{D} \cdot$ Ludovico Mascarin
}

Received: 5 August 2020/ Accepted: 6 January 2021 / Published online: 25 January 2021

(C) The Author(s) 2021

\begin{abstract}
Alkali-activated calcined clays are promising candidates for playing a prominent role in the future construction industry. These binders may achieve excellent mechanical performance, but one issue deserving attention is the proneness to plastic shrinkage and surface cracking. Tackling this issue requires the deployment of laboratory techniques that allow shrinkage-inducing mechanisms to be quantitatively assessed. Here, we demonstrate that time-lapse X-ray imaging can be used to quantify shrinkage immediately after mixing, when the binder is still in its fresh state, with excellent time and space resolution. The numeric quantification of strain is complemented by the real time visual inspection of the displacing sample interface and of the bleed aqueous solution layer that may form. Implementation of this method to a set of alkali-activated cement pastes, prepared by combining calcined clays having different mineralogical composition with sodium silicate activating solutions having different $\mathrm{SiO}_{2} / \mathrm{Na}_{2} \mathrm{O}$ ratios, suggests that two main mechanisms control the early dimensional stability of alkali-activated calcined clays. These mechanisms are: (a) volumetric contraction occurring in response to capillary stress arising from
\end{abstract}

L. Valentini $(\bowtie) \cdot$ L. Mascarin

Department of Geosciences, University of Padua, Padua, Italy

e-mail: luca.valentini@unipd.it

L. Mascarin

e-mail: ludovico.mascarin@phd.unipd.it water evaporation and (b) segregation by particle settling, favoured in the water-saturated regime.

Keywords Plastic shrinkage $\cdot$ Calcined clays · Dimensional stability $\cdot$ Alkali activation $\cdot$ X-ray imaging

\section{Introduction}

Much attention is currently being devoted to calcined clays as key raw materials for the development of sustainable binders. The availability and moderate cost of clays may likely facilitate the deployment of clay-based cements as a sustainable commodity for the future construction industry.

Ternary systems constituted of 50\% Portland cement, blended with calcined clays and limestone [1] are gaining consensus in both academia and the industry, due to the potential of mitigating $\mathrm{CO}_{2}$ emissions and energy consumption, by a production process that does not require enormous adaptations of industrial facilities. Given that the above mentioned alternative cements retain $50 \%$ by mass of Portland cement, going beyond the goal of reducing by half the $\mathrm{CO}_{2}$ emitted by decarbonation, will require the development of binders based on raw materials other than limestone. 
Alkali-activated materials, based on calcined clays or other alumino-silicate reactants, represent one possible class of Portland-free cements that may achieve excellent mechanical properties, although their actual environmental footprint is strongly dependent on the specific formulation adopted and choice of chemical activators [2], which also represent a significant share of the final cost. Nonetheless, overall costs, compared to Portland-based formulations, could be sustainable in geographical areas with limited limestone reserves, where Portland cement (and limestone) must be imported [3].

Clay soils may be particularly suited as starting materials for the production of alkali-activated cement, due to their widespread geographical distribution and relatively low cost [4]. In general, kaolinites represent the most widely used clays in alkaliactivated cements, mostly because of their lower calcination temperature required to induce loss of crystallinity. However, clay mineralogy in soils is strongly dependent on geological and environmental factors that control the intensity of weathering. Kaolinite is mostly concentrated in subequatorial and tropical regions, whereas illites and smectites may be prevalent at other latitudes [5]. Therefore, from a perspective of local sourcing of raw materials, it is worth exploring the performance of alternative binders produced from clay minerals other than kaolinite. It has been shown that alkali-activated materials made from illitic and smectitic clays proved to have adequate strength [6-8]. Despite the excellent mechanical strength of well formulated alkali-activated calcined clays, the performance of these materials is still lagging behind that of Portland cement, when dimensional stability is considered. Quantification of this property, especially at early stage of reaction, has not so far received the same degree of attention as mechanical properties did.

Strain resulting from autogenous shrinkage, creep and water loss is normally larger for alkali-activated materials, as compared to Portland cement [9-11], and may lead to micro-cracking that affects the overall performance. Cracking may appear upon drying shrinkage occurring by loss of water in the hardened state $[11,14,15]$. Likewise, the properties of alkaliactivated cement pastes in the fresh state control the amount of segregation and bleeding [16], which may lead to surface water evaporation and development of plastic shrinkage cracking. This process is initiated by capillary forces arising upon evaporation of the thin superficial water film, which lead to a stress accumulation that may eventually induce cracking once the tensile failure limit is exceeded [17, 18]. Before setting occurs, the stress resulting from capillary pressure can be accommodated by movement of the dispersed particles, which is macroscopically manifested as a displacement of the surface $[19,20]$

In general, it is not trivial, from the technical point of view, to quantitatively measure the strain of cement materials in their fresh state. Existing standard procedures are mostly aimed at evaluating cracking associated with plastic shrinkage [21]. Specific approaches for the evaluation of early shrinkage of cement pastes include indirect methods that measure the volumetric strain based on the displacement of a mass of water surrounding the sample [22]. The only available standard method for the measurement of the early age linear strain of cement and concrete envisages the placement of a plastic ball of about $1 \mathrm{~cm}$ diameter on top of the upper surface and manually measuring the vertical displacement [23]. This method has the limitation of perturbing the interface and only recording vertical strain, with a reported precision of $2.5 \mathrm{~mm}$. Other proposed direct methods for the measurement of plastic shrinkage strain rely on the use of laser sensors [24-27] and transducers [20]. Recently, a measurement method based on the use of optical sensors, embedded within fresh samples, was implemented to the quantification of early age shrinkage in alkali-activated metakaolin [28].

In this technical paper, we present a newly developed method that can be used to easily perform accurate strain measurements in the fresh state, immediately after mixing. The method consists in visualising and quantifying the time-dependent vertical displacement of the upper surface of the sample by means of high-resolution X-ray imaging. Various $\mathrm{X}$-ray imaging techniques, which share the advantage of non-destructive sample preparation, have been used to study morphological aspects of cement materials [29-31]. Here, the continuous collection of X-ray attenuation images with a small time interval provides a high-resolution time-lapse view of the sample interfacial displacement occurring during the early stage of reaction. A similar approach, based on X-ray imaging, was previously used to assess the initiation of plastic shrinkage crack propagation [18], although such an imaging approach has not been used to provide 
a direct visualization of the interface displacement in the fresh state.

Here, the experimental procedure is explained in detail and the robustness of the image processing algorithm used to automatically detect the displacing surface from a sequence of X-ray images is tested using digital samples with known displacement. Preliminary measurements are performed on OPC samples, with the aim of evaluating the precision and accuracy of the method. Finally, we show how this method can be used to quantify the plastic shrinkage of alkali-activated calcined clays of varying composition.

This method can provide insight into the plastic strain of alkali-activated materials and represents an aid to the development of approaches that may mitigate shrinkage and possible subsequent cracking.

\section{Materials and methods}

\subsection{Clays and alkaline activators}

Three clays with different chemical and mineralogical compositions were selected to test the measuring method. Clay 1 (C1) is a red kaolinitic clay soil collected in proximity of Rovinj (Istria peninsula, Croatia). Clay 2 (C2) is a greenish smectitic clay collected in the Vicentine Alps (North-Eastern Italy). Clay 3 (C3) was sampled in Southern Tunisia and is constituted by illite as its major clay mineral phase. The XRF composition of the three clays is displayed in Table 1 . All clays were calcined in a laboratory muffle at $750{ }^{\circ} \mathrm{C}$ for $5 \mathrm{~h}$, with a heating rate of $10{ }^{\circ} \mathrm{C} / \mathrm{min}$. This fixed combination of temperature and time was used for all clays with the aim of minimizing the number of variables present in the system, keeping in mind that unreactive phases form in smectitic and illitic clays above this temperature [6]. The clay mineral fraction was quantified by XRD and Rietveld refinement using the Profex/BGMN package [32]. The disordered structure of the layered silicates was described based on the model files included in the phase analysis software. Before the XRD measurements, the samples were mixed with $10 \%$ internal standard $(\mathrm{ZnO})$ to estimate the amorphous fraction. The quantitative phase analyses returns a composition consisting of $54.7 \%$ kaolinite and $11.6 \%$ illite for $\mathrm{C} 1$; $27.4 \%$ smectite and $2.7 \%$ kaolinite for $\mathrm{C} 2,41.6 \%$ illite and $24.4 \%$ kaolinite for C3. XRD patterns before and after calcination are displayed in Fig. 1. Kaolinite is totally destructured after the thermal treatment, whereas the smectite structure is only partially affected as testified by the persistence of the (001) basal reflection, collapsing from $15.5 \AA\left(6.6^{\circ} 2 \theta\right)$ to $9.8 \AA$ ( $10.4^{\circ} 2 \theta$, dashed lined in Fig. 1). Illite is not strongly affected by calcination at $750{ }^{\circ} \mathrm{C}$ as revealed by the persistence of the main peaks at $10^{\circ}, 23^{\circ}, 40.5^{\circ}$ $2 \theta$. Moreover, the presence of an expandable clay interlayering is suggested by the low-angle asymmetric broadening of the (001) illite peak at $10^{\circ} 2 \theta$, with a shoulder at $11.5 \AA\left(8.9^{\circ} 2 \theta\right.$, dashed lined in Fig. 1). Commercial sodium hydroxide pellets and sodium silicate solution $\left(37.5 \%\right.$ concentration and $2.6 \mathrm{SiO}_{2} /$ $\mathrm{Na}_{2} \mathrm{O}$ ratio) were used to prepare activating alkaline solutions with variable composition $\left(\mathrm{SiO}_{2} / \mathrm{Na}_{2} \mathrm{O}=1.6\right.$ and 2.0). The measured $\mathrm{pH}$ of the two activating solutions was 12.96 and 13.34 for $\mathrm{SiO}_{2} / \mathrm{Na}_{2} \mathrm{O}=2.0$ and 1.6 respectively.

\subsection{Alkali-activated pastes}

The samples used for the strain measurements consisted of small volumes of paste prepared by mixing the three calcined clays with sodium silicate solutions having the $\mathrm{SiO}_{2} / \mathrm{Na}_{2} \mathrm{O}$ ratios mentioned above. This parameter affects the bulk $\mathrm{Si} / \mathrm{Al}$ ratio of the system,

Table 1 XRF chemical composition (wt $\%$ ) of the analysed clays

\begin{tabular}{llllllllllll}
\hline Sample & $\mathrm{SiO}_{2}$ & $\mathrm{TiO}_{2}$ & $\mathrm{Al}_{2} \mathrm{O}_{3}$ & $\mathrm{Fe}_{2} \mathrm{O}_{3}$ & $\mathrm{CaO}$ & $\mathrm{MgO}$ & $\mathrm{MnO}$ & $\mathrm{K}_{2} \mathrm{O}$ & $\mathrm{Na}_{2} \mathrm{O}$ & $\mathrm{P}_{2} \mathrm{O}_{5}$ & $\mathrm{LOI}$ \\
\hline Clay 1 & 52.3 & 1.2 & 23.1 & 8.8 & 0.6 & 0.9 & 0.1 & 1.4 & 0.4 & 0.1 & 11.1 \\
Clay 2 & 62.1 & 0.4 & 15.6 & 4.1 & 0.9 & 1.2 & - & 4.8 & 1.3 & 0.1 & 9.5 \\
Clay 3 & 53.4 & - & 17.9 & 6.7 & 2.8 & 2.3 & - & 0.4 & 4.5 & - & 12.0 \\
\hline
\end{tabular}



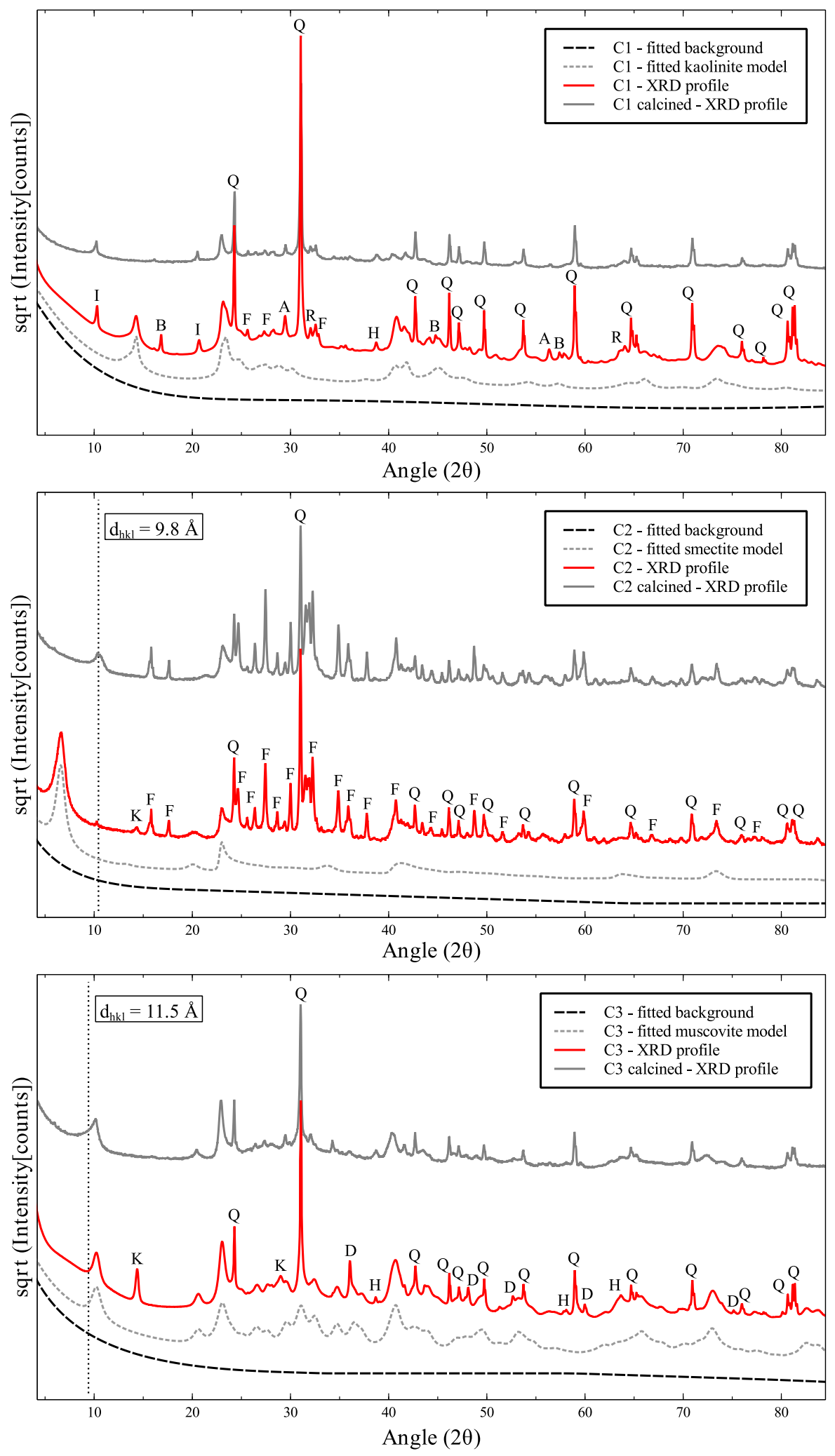
4 Fig. 1 Diffraction profiles (Co radiation) of raw clay (red) and calcined clay (grey). Labels: $\mathrm{K}=$ kaolinite, $\mathrm{I}=$ illite, $\mathrm{Q}=$ quartz, $\mathrm{F}=$ feldspar, $\mathrm{A}=$ anatase, $\mathrm{R}=$ rutile, $\mathrm{H}=$ hematite, $\mathrm{B}=$ boehmite, $\mathrm{D}=$ dolomite. Fitted background and whole profile fitting of kaolinite, smectite and muscovite-2M1 refer to the refinement of the raw clay

which has been shown to play a role in the drying shrinkage of metakaolinite-based alkali-activated materials [11]. Similarly, we attempt to assess the role of the chemical variability on plastic shrinkage. The fraction of clay passing through a sieve of $90 \mu \mathrm{m}$ mesh size was mixed with the alkaline solutions for 2 min and placed in cylindrical plastic holders having $3 \mathrm{~cm}$ height and $1.4 \mathrm{~cm}$ diameter. Two sets of samples were prepared for each of the six formulations: the first one with the sample holder left uncovered and the second one with the sample holder covered with film. This allows the role of evaporation during early reaction (prior to setting) to be assessed. The bulk molar ratios, as calculated with the AMiDsT software [33], water fraction (mass of water divided by total mass of the binder) $\mathrm{w} / \mathrm{T}$ and water/solid ratio $\mathrm{w} / \mathrm{s}$ of the measured samples are reported in Table 2. The amount of water at the numerator of these parameters comprises the water present in the alkaline solution plus any additional water added to the mix. The general notation adopted to refer to each mix is: Cx-yy where $\mathrm{x}$ is a number referring to the clay sample (Clay 1 to Clay 3) and yy is a number that specifies the $\mathrm{SiO}_{2}$ / $\mathrm{Na}_{2} \mathrm{O}$ ratio (1.6 or 2.0) of the activating solution used.

Table 2 Summary of the mix designs for the alkali-activated calcined clays tested, with relevant elemental ratios, water fraction $(\mathrm{w} / \mathrm{T})$, water/solid ratio $(\mathrm{w} / \mathrm{s})$ and silicate modulus $\mathrm{SiO}_{2} / \mathrm{Na}_{2} \mathrm{O}(\mathrm{M})$ of the alkaline solution

\begin{tabular}{lllllll}
\hline Sample & $\mathrm{Na} / \mathrm{Al}$ & $\mathrm{Si} / \mathrm{Al}$ & $\mathrm{H} / \mathrm{Na}$ & $\mathrm{w} / \mathrm{T}$ & $\mathrm{w} / \mathrm{s}$ & $\mathrm{M}$ \\
\hline $\mathrm{C} 1-16$ & 0.95 & 2.66 & 13.91 & 0.31 & 0.60 & 1.6 \\
$\mathrm{C} 2-16$ & 0.95 & 4.04 & 18.55 & 0.31 & 0.54 & 1.6 \\
$\mathrm{C} 3-16$ & 0.95 & 3.27 & 16.57 & 0.31 & 0.57 & 1.6 \\
$\mathrm{C} 1-20$ & 0.87 & 2.77 & 15.30 & 0.31 & 0.63 & 2.0 \\
$\mathrm{C} 2-20$ & 0.87 & 4.12 & 20.25 & 0.31 & 0.56 & 2.0 \\
C3-20 & 0.87 & 3.37 & 18.47 & 0.31 & 0.59 & 2.0 \\
\hline
\end{tabular}

\subsection{Shrinkage measurement}

The evaluation of plastic shrinkage was performed using a novel method (Fig. 2) based on the acquisition of X-ray radiographs at regular time intervals, which allowed the decrease of the sample length, in its fresh state, to be determined. The plastic holders, filled with 5 grams of fresh paste, were immediately placed inside a computed-microtomography scanner. The samples were irradiated by a tungsten radiation, filtered by an aluminium and a copper foil of $0.5 \mathrm{~mm}$ thickness. The beam energy was $100 \mathrm{kV}$, with $2.5 \mathrm{~s}$ exposure time. Attenuation images were collected at fixed rotational angle (i.e. the CT scanner was used to acquire radiographs only, no tomographic reconstruction was performed) by the inbuilt CCD detector of $4000 \times$ 2672 pixels. The length variation was measured on images with a pixel size of $3.45 \mu \mathrm{m}$, acquired with a time interval of $15 \mathrm{~min}$ (the first image for each sample was acquired $10 \mathrm{~min}$ after the beginning of mixing), over a total time span of $3 \mathrm{~h}$. To maximize the signal/ noise ratio, each image was obtained as the average of 12 acquisitions. During all measurements, the ambient relative humidity varied in the range $52-58 \%$ and the temperature at the sample stage varied between 28 and $30{ }^{\circ} \mathrm{C}$.

This setup allows the very early stages of plastic strain to be measured. In principle, the measurement can be carried out with time steps as small as $1 \mathrm{~min}$. Moreover, although longer time spans can be measured, the goal of the present investigation was measuring shrinkage prior to setting.

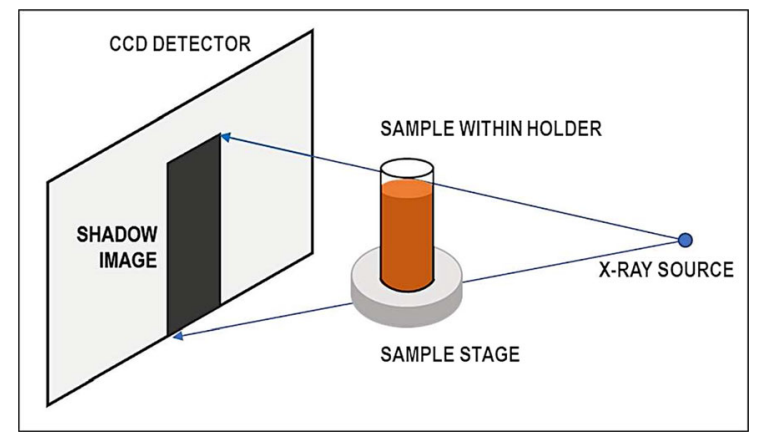

Fig. 2 Sketch of the experimental setup adopted for the measurement of plastic strain. The sample is irradiated by a cone-shaped X-ray beam. The incident radiation is partly attenuated by the sample and projects a shadow image on the CCD detector. Shadow images collected at different times are then used to calculate strain 
Compared to the ASTM C827 standard method [23], the sample size used in this study $(1.4 \mathrm{~cm}$ diameter) was smaller, given that cement paste cylindrical samples with $5 \mathrm{~cm}$ diameter are recommended by the ASTM C827 standard. In principle, samples of larger sizes can be measured by the method illustrated in the present study, with a subsequent loss in spatial resolution and hence accuracy. Small-sized samples also enhance the role of menisci, forming by interaction between sample and sample holder, during interface displacement. It has been previously stressed how such menisci play a fundamental role in determining the early cracking behaviour in restrained specimens [34] and that larger stresses are developed in smaller samples [35]. Therefore, samples of relatively small size may facilitate the assessment of the effect of stresses associated with the formation of menisci.

\subsection{Image processing and strain calculation}

The sequence of images acquired at each time interval are used to evaluate the vertical displacement of the upper surface of the sample with respect to the position of the surface for the first acquired image (10 min after the beginning of mixing), which is used as a reference. The time-dependent strain is obtained by dividing the value of the displacement at each time step by the initial length of the sample, which is measured on a preliminarily acquired low-magnification X-ray image. Adhesion to the sample holder walls results in the formation of a meniscus at the interface between sample and air. Therefore, the vertical position of the surface is not constant along the plane perpendicular to the vertical direction. Likewise, the value of the displacement at each time step is not constant and will tend to increase from the sample holder walls towards the centre of the interface. Hence, the time-dependent displacement $d(t)$ is calculated as the mean value along the horizontal direction of the X-ray image.

To automatically evaluate the displacement at each point along the horizontal direction, we devised an algorithm that tracks the position of the interface between sample and air by detecting significant discontinuities of greyscale values within the X-ray image. Such discontinuities correspond to variations of the X-ray linear attenuation coefficient, which has a finite value for the sample and vanishes for air.

To better illustrate these concepts and to validate our algorithm, a digital sample with known displacement was created. This consists of a greyscale image in which the "sample" is represented by black pixels and the surrounding air by grey pixels. To simulate the interaction between sample and the walls of the sample holder, a quadratic function was used to obtain a curved interface (Fig. 3a). This interface was displaced by an extent proportional to the distance from the wall (Fig. 3b). Specifically, the amount of vertical displacement varied from 55 to 81 pixels. To evaluate the performance of the interface tracking algorithm, Gaussian noise was added to the images, to simulate the effect of instrumental noise present in $\mathrm{X}$-ray images (Fig. 3c, d). These latter images were then used to retrieve the value of displacement, as evaluated by our algorithm. As anticipated, this algorithm evaluates the position of the interface by detecting discontinuities in greyscale values (Fig. 4) across the image $[36,37]$. The estimated displacement (Fig. 5) varies between 54 and 83 pixels, whereas the actual displacement was 81 pixels at the centre of the
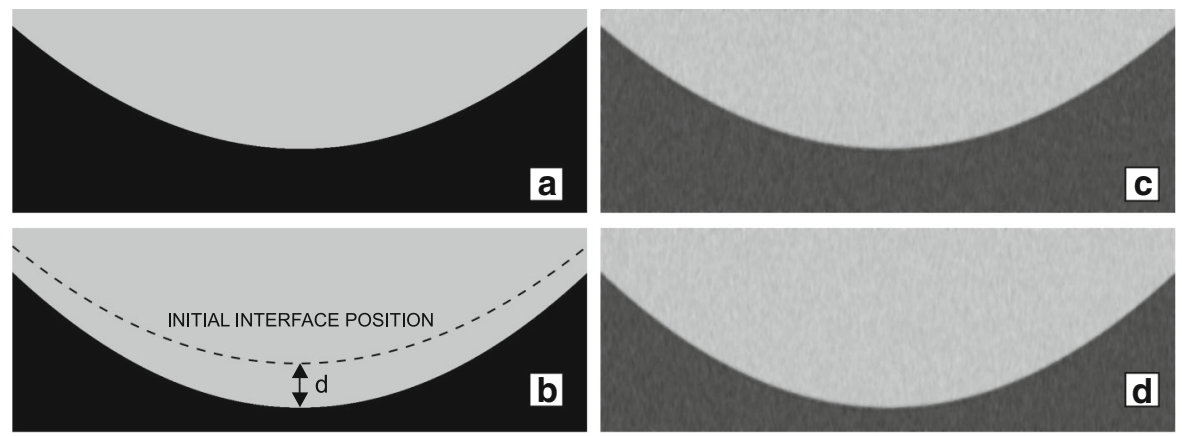

Fig. 3 Digital simulated X-ray image used to test the interface-tracking algorithm: initial interface position (a); interface position after displacement. The extent of displacement $d$ in the central position is shown (b). Same images with Gaussian noise added (c, d) 


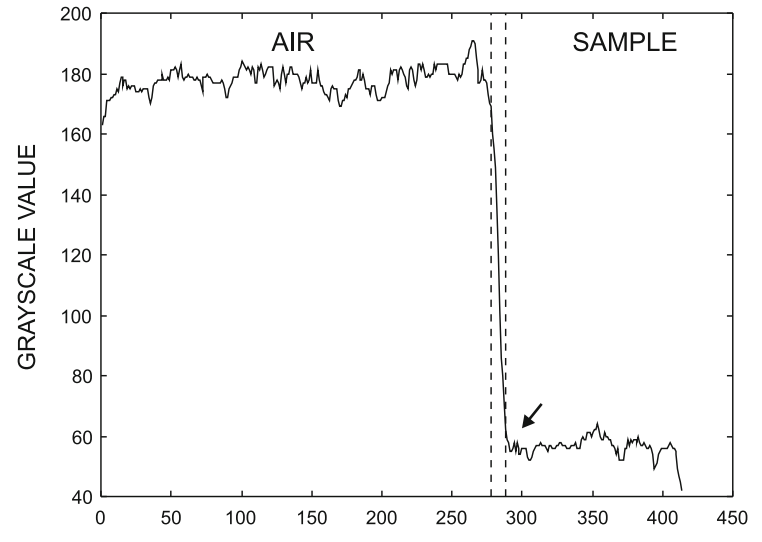

VERTICAL POSITION AT THE CENTRE OF THE IMAGE (PIXEL)

Fig. 4 Variation of the greyscale value from top to bottom of the vertical transect running through the centre of the image displayed in Fig. 3c. The dashed lines represent the automatically detected discontinuities. The position of the interface corresponds to the second discontinuity (marked with an arrow), which is where the value of X-ray attenuation matches that of the sample

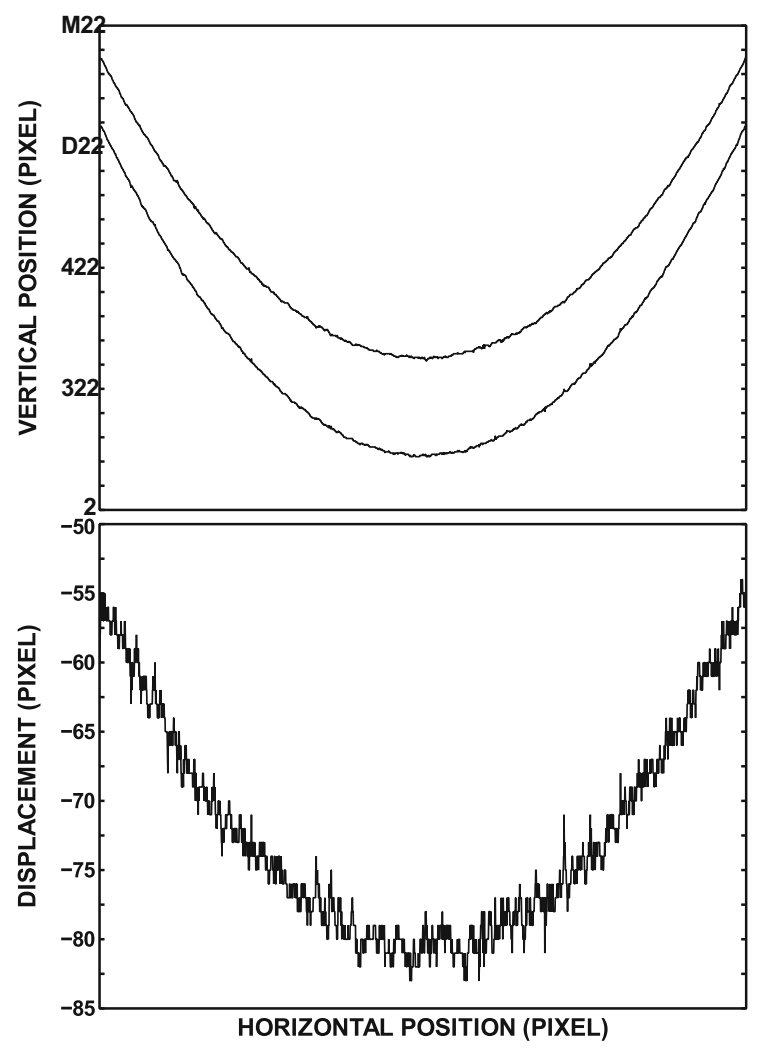

Fig. 5 Estimated position of the interfaces relative to the images displayed in Fig. 2c, d (top) and estimated displacement along the horizontal direction (bottom)

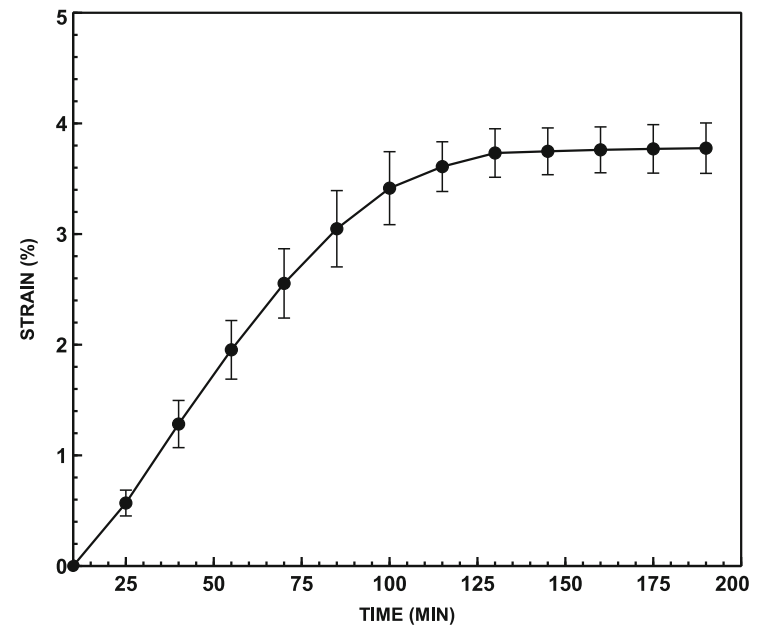

Fig. 6 Strain $\%$ vs. time for the OPC test sample. The data points are averaged over three measurements. The size of the error bars is $\pm \mathrm{SD}$

images and 55 pixels at the boundaries. The average estimated displacement is 72 pixels with a standard deviation of 8 .

\section{Results}

The results of preliminary tests, performed on an ordinary Portland cement with w/c $=0.45$, are displayed in Fig. 6, in which strain (averaged over three repeated measurements) is plotted versus time. The measured strain increases with a nearly constant rate for approximately the first $1.5 \mathrm{~h}$, then with a decreasing rate until reaching a plateau of about $3.7 \%$ strain after approximately $130 \mathrm{~min}$, which is likely due to the occurrence of set (the initial setting time measured by Vicat needle for the used OPC is 150 $\mathrm{min})$. The strain measured at plateau is in the range of values of vertical displacement plastic strain for OPC, between 1 and 4\%, previously measured using LVDT sensors [20].

\subsection{Alkali-activated calcined clays: unsealed samples}

A set of images displaying the position of the interface after 10 and 190 min since mixing, for the measured samples are displayed in Fig. 7. Examples of timelapse animations displaying the surface displacement 
a
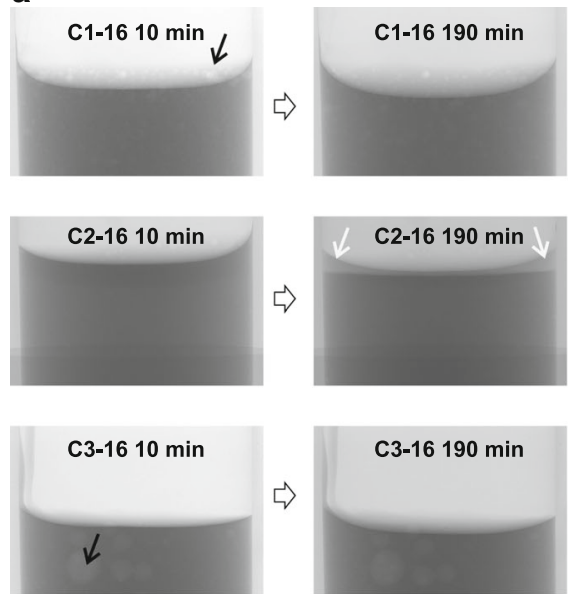

Fig. 7 X-ray attenuation images of the unsealed samples. For each sample, the first (10 min after mixing) and last (190 min after mixing) acquisition is displayed. a Calcined clays activated with $1.6 \mathrm{SiO}_{2} / \mathrm{Na}_{2} \mathrm{O}$ solution; a Calcined clays activated with
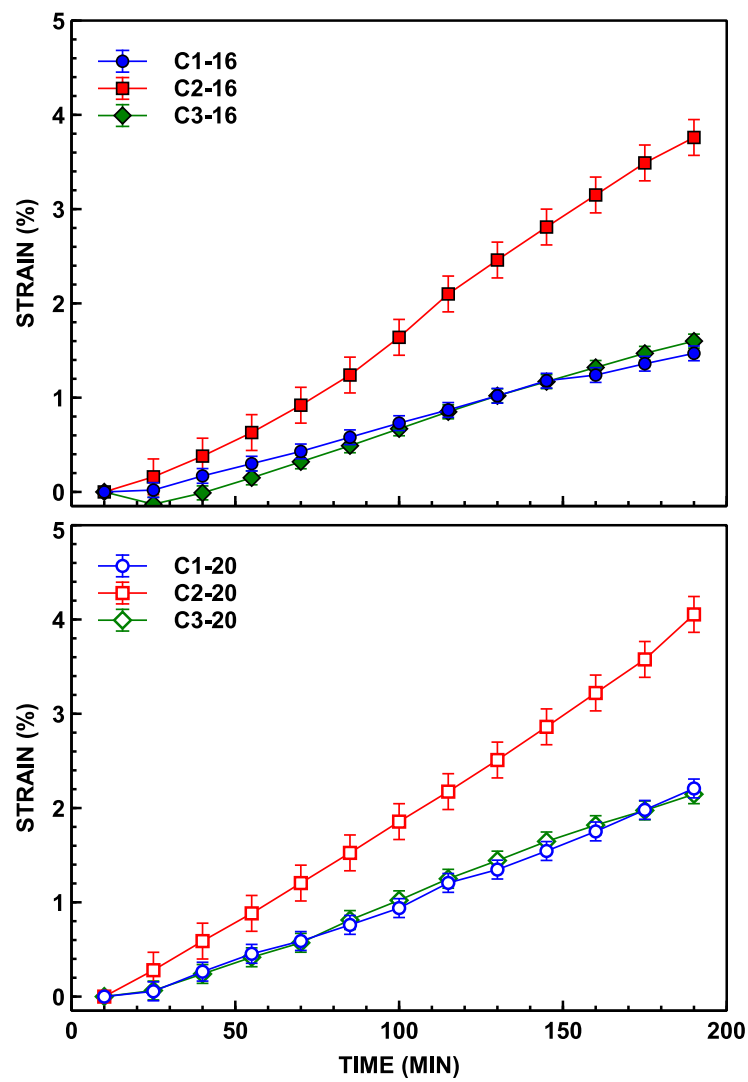

Fig. 8 Time-dependent strain for the calcined clays activated with $1.6 \mathrm{SiO}_{2} / \mathrm{Na}_{2} \mathrm{O}$ solution (top) and $2.0 \mathrm{SiO}_{2} / \mathrm{Na}_{2} \mathrm{O}$ solution (bottom) in unsealed conditions. Error bars correspond to the average error estimated for the OPC test sample b
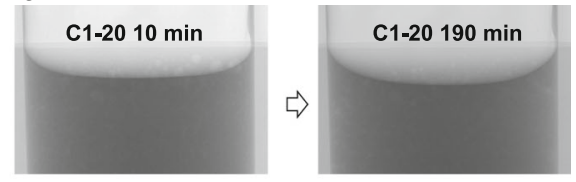

C2-20 $10 \mathrm{~min}$

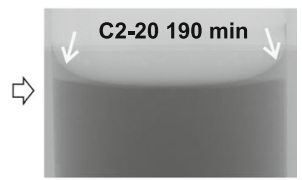

C3-20 $10 \mathrm{~min}$

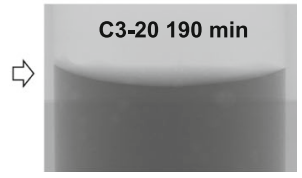

2.0 $\mathrm{SiO}_{2} / \mathrm{Na}_{2} \mathrm{O}$ solution. Light-coloured arrows point to the film of solution forming by bleeding in the samples prepared from Clay 2. Black-coloured arrows point to air bubbles

with time, and the full dataset of X-ray images (sealed and unsealed) are available at the Research Data UNIPD repository (http://researchdata.cab.unipd.it/ 363/).

The position of the interface between samples and air, forming more or less curved menisci, is clearly visible. The circular features that can be observed in all samples represent air bubbles forming between the outer surface of the sample holder and the adhesive tape used to hold the sample holder firm within the CT scanner.

The time-dependent strain of the measured unsealed samples is displayed in Fig. 8. The plastic strain values increase with nearly linear rate for all samples during the whole measurement time span. The time evolution for the samples prepared from Clay 1 and Clay 3 are overlapping, achieving a maximum strain, after 190 min since mixing, between 1.5 and $1.6 \%$ when activated with the $1.6 \mathrm{SiO}_{2} / \mathrm{Na}_{2} \mathrm{O}$ solution, and between 2.1 and $2.2 \%$ when activated with the 2.0 $\mathrm{SiO}_{2} / \mathrm{Na}_{2} \mathrm{O}$ solution. The strain measured for the samples prepared from Clay 2 is significantly higher, with maximum values of $3.8 \%$ and $4.1 \%$ for activating solutions with 1.6 and $2.0 \mathrm{SiO}_{2} / \mathrm{Na}_{2} \mathrm{O}$ respectively. Compared to the previous ones, this latter sample also displays, at the end of the measurement, a thin layer of bleed solution forming at the interface (Fig. 7). Possible explanations for these observed differences will be provided in the discussion section. 
a
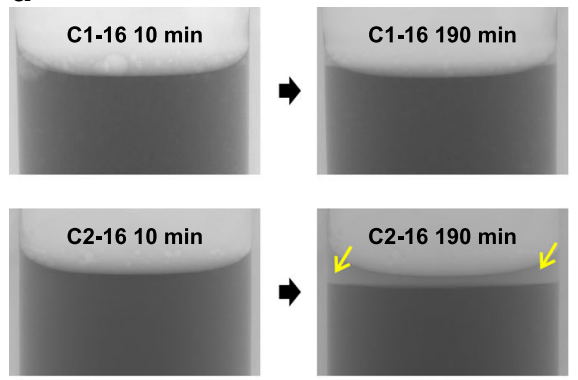

C3-16 $10 \mathrm{~min}$
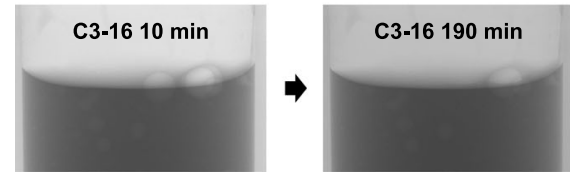

Fig. 9 X-ray attenuation images of the sealed samples. For each sample, the first (10 min after mixing) and last (190 min after mixing) acquisition is displayed. a Calcined clays activated with

\subsection{Alkali-activated calcined clays: sealed samples}

The behaviour of the sealed alkali-activated samples is more complex compared to the unsealed ones, and strongly dependent upon the combination of specific calcined clay and activating solution used. In this case, wrapping of the sample holder with a sealing film prevents evaporation and creates a water-saturated environment above the upper sample surface.

Images of the samples at 10 and $190 \mathrm{~min}$ after mixing are displayed in Fig. 8. As observed for the unsealed C2-16 and C2-20 samples, the presence of a film of activating solution is clearly visible in sealed samples C2-16 and C2-20. The height of this bleeding layer is bigger compared to the same samples prepared in unsealed conditions, which is expected since sealing prevents evaporation. Contrary to what observed for the unsealed sample, a thick bleeding layer is observed for the $\mathrm{C} 3$ sample, but only when the $2.0 \mathrm{SiO}_{2} / \mathrm{Na}_{2} \mathrm{O}$ solution is used.

The time-dependent strain is displayed in Fig. 10. For samples $\mathrm{C} 1$, the strain is significantly smaller than that observed in unsealed conditions, with the value at 190 min varying between $0.40 \%(\mathrm{C} 1-16)$ and $0.67 \%$ (C1-20). For samples C2, the overall behaviour is similar to what observed for the unsealed samples, except the fact that in this case, a larger amount of strain is observed for the sample activated with the 1.6 $\mathrm{SiO}_{2} / \mathrm{Na}_{2} \mathrm{O}$ solution. For sample $\mathrm{C} 3$, the behaviour is b

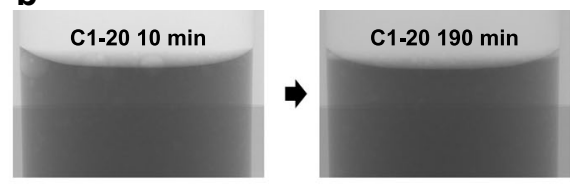

C2-20 $10 \mathrm{~min}$

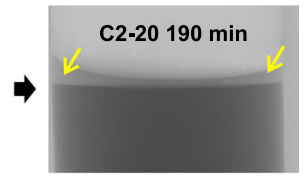

C3-20 $10 \mathrm{~min}$

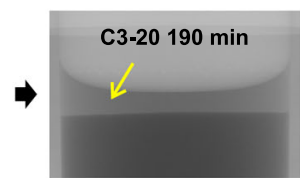

1.6 $\mathrm{SiO}_{2} / \mathrm{Na}_{2} \mathrm{O}$ solution; b Calcined clays activated with 2.0 $\mathrm{SiO}_{2} / \mathrm{Na}_{2} \mathrm{O}$ solution. Light-coloured arrows point to the film of solution forming by bleeding

particularly complex, since a very limited extent of strain $(0.06 \%)$ is observed for sample C3-16, activated with the $1.6 \mathrm{SiO}_{2} / \mathrm{Na}_{2} \mathrm{O}$ alkaline solution, whereas a strain as large as $11.6 \%$ is observed for sample C3-20, activated with the $2.0 \mathrm{SiO}_{2} / \mathrm{Na}_{2} \mathrm{O}$ alkaline solution.

\section{Discussion}

In this section we will briefly discuss possible implications, based on the results of the plastic shrinkage measurements, for the mechanisms of alkali-activated calcined clay early stage reactions. In doing so, we remind that the main goal of this study was assessing the potential of this experimental approach in the investigation of shrinkage occurring in the fresh state. Integrating this imaging approach with complementary measurements such as setting time, calorimetry, porosimetry and rheometry would provide a comprehensive picture of the early age reaction in specific case studies, though being outside the scope of the present research.

In the fresh state, strain is controlled by the following machanisms: (a) autogenous shrinkage, which at early ages corresponds to chemical shrinkage [38]; (b) capillary stresses associated with evaporation, which has been observed to induce the formation of vertical moisture gradients at early ages [39, 40]; (c) gravity-induced particle settling. 


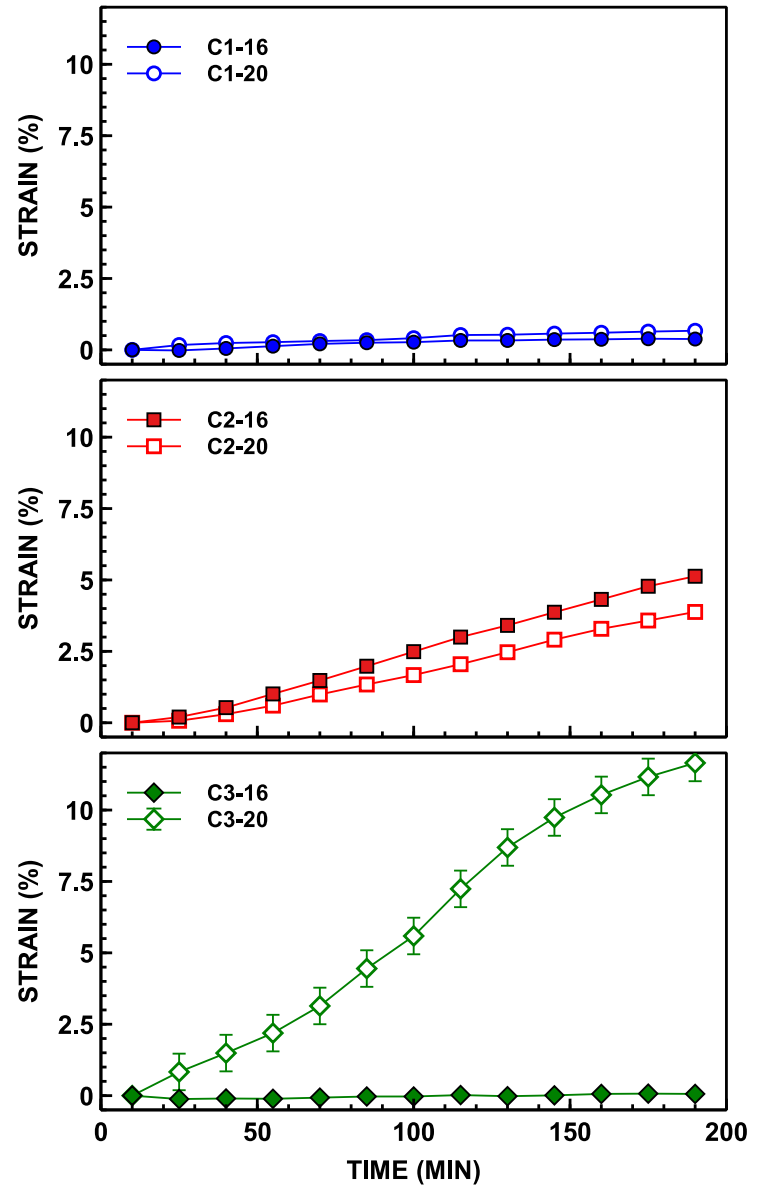

Fig. 10 Time-dependent shrinkage for the calcined clays activated with $1.6 \mathrm{SiO}_{2} / \mathrm{Na}_{2} \mathrm{O}$ solution (top) and $2.0 \mathrm{SiO}_{2} /$ $\mathrm{Na}_{2} \mathrm{O}$ solution (bottom) in sealed conditions. Error bars correspond to the average error estimated for the OPC test sample. The error bars are smaller than the size of the symbols for all samples except C3-20

For the unsealed samples, evaporation of the aqueous solution at the interface may occur at a faster pace compared to the rate of migration of the aqueous solution to the upper surface. This regime of the reacting system has also been defined "drying state" [41]. When the film of aqueous solution present at the upper surface begins to evaporate, arising capillary forces act on the suspended particles, resulting in a net contraction [19, 20, 42]. The rate of evaporation in unsealed conditions was estimated by an X-ray timelapse acquisition (Fig. 11) of a sample consisting of $4 \mathrm{~g}$ of sodium silicate solution $\left(\mathrm{SiO}_{2} / \mathrm{Na}_{2} \mathrm{O}=1.6\right)$ and no solids, from which a linear evaporation rate of 2 $\mu \mathrm{mol} \mathrm{m}^{-2} \mathrm{~s}^{-1}$ was calculated.

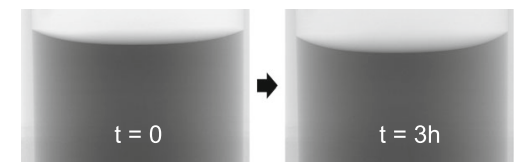

Fig. $11 \mathrm{X}$-ray imaging of the alkaline solution at 0 and $3 \mathrm{~h}$, displaying volume reduction due to evaporation

For samples $\mathrm{C} 1$ and $\mathrm{C} 3$, measured in unsealed conditions, no layer of aqueous solution is observed at the interface, suggesting that the contribution of particle settlement is minor and that the estimated strain is likely resulting from the above mentioned capillary pressure. Samples C2, on the other hand, present a much larger extent of strain (more than twice the strain of samples $\mathrm{C} 1$ and C3) and a thin layer of aqueous solution is visible at the interface (Fig. 7) suggesting that the rate of bleeding is faster than the rate of evaporation. In this case, the segregation of solid particles by gravity-induced settlement has likely played a relevant role in determining the observed plastic shrinkage. Particle settlement has long been recognized as a mechanism that controls the behaviour of fresh cement [43]. This tendency to settling and segregation of samples $\mathrm{C} 2$ is related to the intrinsic lower reactivity of this sample, which is characterized by a lower $\mathrm{Al}_{2} \mathrm{O}_{3} / \mathrm{SiO}_{2}$ ratio, indicative of a larger amount of inert phases such as feldspars and quartz, compared to samples $\mathrm{C} 1$ and $\mathrm{C} 3$ prepared using Clay 1 and Clay 3. This is confirmed by the results of semi-adiabatic calorimetry measurements that show the limited degree of early reactivity for sample $\mathrm{C} 2$, as compared to samples C1 and C3 (Fig. 12). Such a lower reactivity results in reduced precipitation of reaction products, which induce the development of attractive interparticle forces. Subsequently, the suspension presents a worse colloidal stability prior to the occurrence of setting.

Likewise, the overall larger strain observed for all unsealed samples activated by the $2.0 \quad \mathrm{SiO}_{2} / \mathrm{Na}_{2} \mathrm{O}$ alkaline solution may also be explained by a lower system reactivity in the presence of a lower $\mathrm{pH}$, which may slightly increase the contribution of particle settlement. An initial slower reactivity in the presence of solutions with higher $\mathrm{SiO}_{2} / \mathrm{Na}_{2} \mathrm{O}$ ratio has also been shown by numerical simulations of alkali-activated metakaolinite reaction kinetics [44].

The results relative to the samples measured in sealed conditions can be interpreted as occurring in 


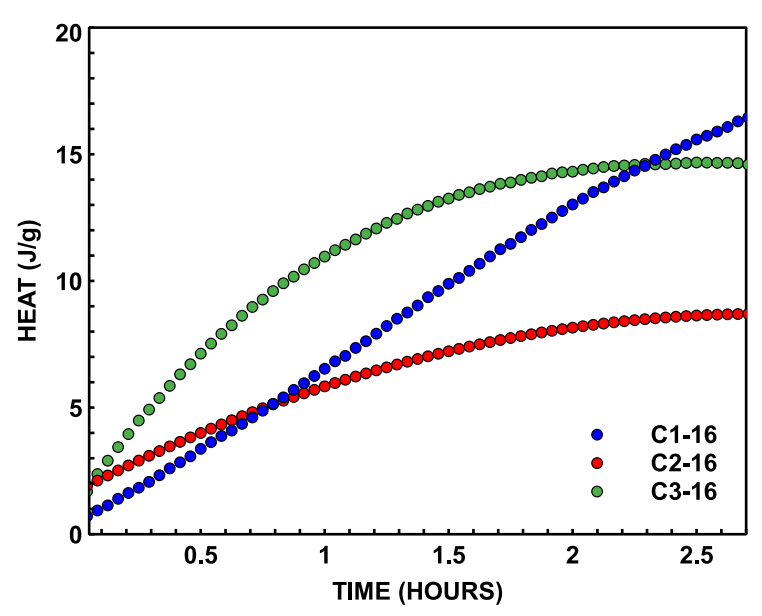

Fig. 12 Early-age enthalpy of reaction measured by semiadiabatic calorimetry for samples C1-16, C2-16, C3-16

what has been defined "bleeding regime" [41]. In the absence of water evaporation, the colloidal stability is primarily controlled by attractive interactions occurring as a consequence of the formation of reaction products [41]. The low amount of plastic shrinkage observed for samples C1-16 and C1-20 in sealed conditions can be ascribed to a sufficient early reactivity, which conferred a good colloidal stability to the suspension in both sealed and unsealed conditions. The lack of capillary pressures arising from evaporation of the aqueous phase resulted in a decreased overall strain compared to the corresponding unsealed samples.

The sealed C3-16 sample behaved similarly to the sealed samples C1-16 and C1-20, with a very limited extent of plastic shrinkage observed. On the contrary, the sealed C3-20 sampled displayed the largest measured amount of strain, accompanied by the formation of a thick layer of aqueous solution at the interface. This behaviour has to be probably ascribed to poor calcined clay reactivity in the $2.0 \mathrm{SiO}_{2} / \mathrm{Na}_{2} \mathrm{O}$ activating solution, characterized by a lower $\mathrm{pH}$. In this case, in the absence of cohesive forces induced by the formation of a sufficient amount reaction product, particle settlement represented the driving force leading to segregation and plastic shrinkage. The lack of water evaporation hindered the development of an increased effective particle packing and the establishment of colloidal interactions, which may have favoured particle cohesiveness in unsealed conditions. The poorer reactivity of Clay $\mathrm{C} 3$, in the presence of the
$2.0 \mathrm{SiO}_{2} / \mathrm{Na}_{2} \mathrm{O}$ activating solution, as compared to Clay $\mathrm{C} 1$, is due to the mineralogical composition of the clay, mainly consisting of illite, which tends to be less reactive than kaolinite [4, 45]. The sealed C2 samples behave similarly to what observed for the corresponding unsealed samples for what concerns the development of a visible bleeding layer. However, contrary to what observed for the unsealed samples, in this case the extent of plastic shrinkage decreases as the $\mathrm{SiO}_{2} / \mathrm{Na}_{2} \mathrm{O}$ increases. A possible explanation is that when evaporation is allowed (drying regime), the net reduction of the water volume favours colloidal interactions, which was also the case of sample C3-20. Previous rheological measurements supported this hypothesis, showing that viscosities measured at different vertical positions within a given samples, in the presence of bleeding, varied, with viscosity being higher in the bottom parts of the sample where the occurrence of bleeding induced a local increase in the packing density [46]. Therefore, for sample C2 in unsealed conditions, particle interaction is favoured by evaporation and, apparently, the amount of shrinkage is mostly controlled by the degree of reactivity, with the sample reacting in the higher $\mathrm{pH}$ solution displaying a slightly lower amount of shrinkage. On the contrary, in the water saturated state (bleeding regime) segregation becomes the dominant factor and in this case the viscosity of the suspended liquid, which is proportional to the $\mathrm{SiO}_{2} / \mathrm{Na}_{2} \mathrm{O}$ ratio [47], may control the extent of particle settlement.

\section{Conclusions}

We have presented a time-lapse X-ray imaging method for the study of shrinkage occurring in the early stage of cement reaction, prior to setting. Strain can be measured in real time, with micrometre spatial resolution. Compared to other methods, this approach has the advantage of providing real images of the displacing sample interface, by which the quantitative evaluation of strain can be complemented by a visual inspection, with excellent precision.

The relatively large water requirement needed for alkali-activated calcined clays to achieve adequate workability may potentially expose these binders to plastic shrinkage and early cracking, particularly for those mixes characterized by slow early reactivity, which results in a limited extent of paste cohesiveness. 
By implementing the measuring method illustrated in this study to a set of different alkali-activated clay mixes, it is suggested that the main mechanisms that may induce plastic shrinkage are: (a) capillary stresses arising when the rate of evaporation is faster than the bleeding rate (drying regime) and (b) particle settlement, enhanced in the water saturated regime. These results may have implications for the adoption of specific curing conditions, when producing alkaliactivated calcined clays, aimed at minimizing the occurrence of plastic shrinkage and possible cracking. For instance, as observed in this study, curing in sealed conditions may minimize plastic shrinkage of the most reactive systems and maximize that of the less reactive ones.

It has been observed that differences in clay mineralogy may result in significantly different behaviours in terms of plastic shrinkage, which in general appears to be controlled by the interplay of early age reactivity, amount of water and viscosity of the suspending solution. It is therefore recommended that, for specific case studies, this approach is integrated with additional measurements aimed at providing a comprehensive view of the early age behaviour of the studied system. Given the importance of colloidal interaction in controlling early dimensional stability, rheological measurements may provide complementary information to underpin the envisaged mechanisms of shrinkage in the fresh state $[48,46]$.

Acknowledgements Chedlia Ounissi (University of Gabès) is acknowledged for kindly providing the Tunisian clays.

Funding Open Access funding provided by Università degli Studi di Padova.

\section{Compliance with ethical standards}

Conflict of interest The authors declare that they have no conflict of interest.

Open Access This article is licensed under a Creative Commons Attribution 4.0 International License, which permits use, sharing, adaptation, distribution and reproduction in any medium or format, as long as you give appropriate credit to the original author(s) and the source, provide a link to the Creative Commons licence, and indicate if changes were made. The images or other third party material in this article are included in the article's Creative Commons licence, unless indicated otherwise in a credit line to the material. If material is not included in the article's Creative Commons licence and your intended use is not permitted by statutory regulation or exceeds the permitted use, you will need to obtain permission directly from the copyright holder. To view a copy of this licence, visit http://creativecommons.org/licenses/by/4.0/.

\section{References}

1. Antoni M, Rossen J, Martirena F, Scrivener K (2012) Cement substitution by a combination of metakaolin and limestone. Cem Concr Res 42(12):1579-1589

2. Habert G, Ouellet-Plamondon C (2016) Recent update on the environmental impact of geopolymers. RILEM Tech Lett 1:17-23

3. Provis JL (2018) Alkali-activated materials. Cem Concr Res 114:40-48

4. Khalifa AZ, Cizer Özlem, Y. Pontikes, A. Heath, P. Patureau, S.A. Bernal, A.T. Marsh (2020) Advances in alkali-activation of clay minerals. Cem Concr Res 132:106050

5. Ito A, Wagai R (2017) Global distribution of clay-size minerals on land surface for biogeochemical and climatological studies. Sci Data 4:170103

6. Buchwald A, Hohmann M, Posern K, Brendler E (2009) The suitability of thermally activated illite/smectite clay as raw material for geopolymer binders. Appl Clay Sci 46(3):300-304

7. Dietel J, Warr LN, Bertmer M, Steudel A, Grathoff GH, Emmerich K (2017) The importance of specific surface area in the geopolymerization of heated illitic clay. Appl Clay Sci 139:99-107

8. Valentini L, Contessi S, Dalconi MC, Zorzi F, Garbin E (2018) Alkali-activated calcined smectite clay blended with waste calcium carbonate as a low-carbon binder. J Clean Prod 184:41-49

9. Hojati M, Rajabipour F, Radlińska A (2019) Drying shrinkage of alkali-activated cements: effect of humidity and curing temperature. Mater Struct 52(6):118

10. Hu X, Shi C, Zhang Z, Hu Z (2019) Autogenous and drying shrinkage of alkali-activated slag mortars. J Am Ceram Soc 102(8):4963-4975

11. Kuenzel C, Vandeperre LJ, Donatello S, Boccaccini AR, Cheeseman C (2012) Ambient temperature drying shrinkage and cracking in metakaolin-based geopolymers. J Am Ceram Soc 95(10):3270-3277

12. Mastali M, Kinnunen P, Dalvand A, Firouz RM, Illikainen M (2018) Drying shrinkage in alkali-activated binders-a critical review. Constr Build Mater 190:533-550

13. Nedeljkovic M, Li Z, Ye G (2018) Setting, strength, and autogenous shrinkage of alkali-activated fly ash and slag pastes: effect of slag content. Materials 11:2121

14. Perera D, Uchida O, Vance E (2007) Influence of curing schedule on the integrity of geopolymers. J Mater Sci 421:3099-3106

15. Zuhua Z, Xiao Y, Huajun Z, Yue C (2009) Role of water in the synthesis of calcined kaolin-based geopolymer. Appl Clay Sci 43(2):218-223

16. Chindaprasirt P, Cao T (2015) Setting, segregation and bleeding of alkali-activated cement, mortar and concrete binders. In: Pacheco-Torgal F, Labrincha J, Leonelli C, Palomo A, Chindaprasirt P (eds) Handbook of alkali- 
activated cements, mortars and concretes. Woodhead Publishing, Oxford, pp 113-131

17. Ghourchian S, Wyrzykowski M, Lura P (2017) A practical approach for reducing the risk of plastic shrinkage cracking of concrete. RILEM Techl Lett 2:40-44

18. Ghourchian S, Wyrzykowski M, Plamondon M, Lura P (2019) On the mechanism of plastic shrinkage cracking in fresh cementitious materials. Cem Concr Res 115:251-263

19. Boshoff WP, Combrinck R (2013) Modelling the severity of plastic shrinkage cracking in concrete. Cem Concr Res 48:34-39

20. Slowik V, Schmidt M, Fritzsch R (2008) Capillary pressure in fresh cement-based materials and identification of the air entry value. Cem Concr Compos 30(7):557-565

21. Sayahi F, Emborg M, Hedlund HGB (2017) Plastic shrinkage cracking in concrete: influence of test methods. In: 2nd international RILEM/COST conference on early age cracking and serviceability in cement-based materials and structures-EAC2. Brussels, Belgium

22. Bjøntegaard $\varnothing$, Hammer T, Sellevold EJ (2004) On the measurement of free deformation of early age cement paste and concrete. Cem Concr Compos 26(5):427-435

23. ASTM: Standard test method for change in height at early ages of cylindrical specimens of cementitious mixtures. Tech. Rep. C827 (2016)

24. Darquennes A, Khokhar M, Rozière E, Loukili A, Grondin F, Staquet S (2011) Early age deformations of concrete with high content of mineral additions. Constr Build Mater 25(4):1836-1847

25. Ghoddousi P, Javid A (2012) Effect of reinforcement on plastic shrinkage and settlement of self-consolidating concrete as repair material. Mater Struct 45:41-52

26. Kwak HG, Ha S, Weiss WJ (2010) Experimental and numerical quantification of plastic settlement in fresh cementitious systems. J Mater Civ Eng 22(10):951-966

27. Yang K, Zhong M, Magee B, Yang C, Wang C, Zhu X, Zhang Z (2017) Investigation of effects of Portland cement fineness and alkali content on concrete plastic shrinkage cracking. Constr Build Mater 144:279-290

28. Palumbo G, Di Palma P, Iadicicco A, Messina F, Farina I, Colangelo F, Ferone C, Cioffi R, Campopiano S (2019) Fiber Bragg grating sensors for real time monitoring of early age curing and shrinkage of different metakaolin-based inorganic binders. IEEE Sens J 19(15):6173-6180

29. Clark S, Morrison G, Shi W (1999) The use of scanning transmission X-ray microscopy for the real-time study of cement hydration. Cem Concr Res 29(7):1099-1102

30. Parisatto M, Dalconi M, Valentini L, Artioli G, Rack A, Tucoulou R, Cruciani G, Ferrari G (2015) Examining microstructural evolution of Portland cements by in-situ synchrotron micro-tomography. J Mater Sci 50:1805-1817

31. Silva DA, Monteiro PJ (2006) The influence of polymers on the hydration of Portland cement phases analyzed by soft
X-ray transmission microscopy. Cem Concr Res 36(8):1501-1507

32. Doebelin N, Kleeberg R (2015) Profex: a graphical user interface for the Rietveld refinement program BGMN. J Appl Crystallogr 48(5):1573-1580

33. Valentini L (2020) AMiDsT v1.0 alkali-activated-materials mix design tool. https://doi.org/10.13140/RG.2.2.18905. 47200/1

34. Turcry P, Loukili A (2006) Evaluation of plastic shrinkage cracking of self-consolidating concrete. ACI Mater J 103:272-279

35. Weiss W, Yang W, Shah S (2000) Influence of specimen size/geometry on shrinkage cracking of rings. J Eng Mech 126:93-101

36. Killick R, Fearnhead P, Eckley IA (2012) Optimal detection of changepoints with a linear computational cost. J Am Stat Assoc 107(500):1590-1598

37. Lavielle M (2005) Using penalized contrasts for the changepoint problem. Signal Process 85(8):1501-1510

38. Bouasker M, Mounanga P, Turcry P, Loukili A, Khelidj A (2008) Chemical shrinkage of cement pastes and mortars at very early age: effect of limestone filler and granular inclusions. Cem Concr Compos 30(1):13-22

39. Šelih J, Bremmer T (1996) Drying of saturated lightweight concrete: an experimental investigation. Mater Struct 29:401

40. Šelih J, Sousa A, Bremmer T (1996) Moisture transport in initially fully saturated concrete during drying. Transp Porous Med 24:81-106

41. Ghourchian S, Wyrzykowski M, Lura P (2018) A poromechanics model for plastic shrinkage of fresh cementitious materials. Cem Concr Res 109:120-132

42. Wittmann F (1976) On the action of capillary pressure in fresh concrete. Cem Concr Res 6(1):49-56

43. Wheeler J (1966) Mechanism of settling in cement paste. Cem Concr Res 212:1035-1036

44. Valentini L (2018) Modeling dissolution-precipitation kinetics of alkali-activated metakaolin. ACS Omega 3(12):18100-18108

45. Khalifa AZ, Pontikes Y, Elsen J, Cizer O (2019) Comparing the reactivity of different natural clays under thermal and alkali activation. RILEM Tech Lett 4:74-80

46. von Bronk T, Haist M, Lohaus L (2020) The influence of bleeding of cement suspensions on their rheological properties. Materials 13:1609

47. Vail J (1952) Soluble silicates: their properties and uses. Reinhold, New York

48. Bellotto M (2013) Cement paste prior to setting: a rheological approach. Cem Concr Res 52:161-168

Publisher's Note Springer Nature remains neutral with regard to jurisdictional claims in published maps and institutional affiliations. 